\title{
Direct and Moderating Effects of Sexual Minority Identity Dimensions on Mental Health
}

\author{
Emma G. Fredrick and Stacey L. Williams ${ }^{1}$
}

Sexual minorities experience minority stress, which is associated with mental health disparities. However, specific dimensions of identity may buffer against these disparities. While research in other stigmatized populations has found evidence for direct and moderating effects of identity on mental health, limited research has examined these dimensions in sexual minorities. We explored the potential direct and moderating effects of identity dimensions with regards to sexual stigma and mental health. Findings from 209 lesbian, gay, and bisexual individuals revealed higher centrality of sexual orientation identity and more positive private regard predicted lower psychological distress and more positive private regard predicted higher self-esteem. Additionally, centrality moderated the effect of public stigma, such that those who reported higher centrality did not report decrements to self-esteem in the face of public stigma to the extent of those with low centrality. Findings suggest centrality and private regard contribute to the psychological wellbeing of sexual minorities. [Article copies available for a fee from The Transformative Studies Institute. E-mail address: journal@transformativestudies.org Website: http://www.transformativestudies.org 02021 by The Transformative Studies Institute. All rights reserved.]

KEYWORDS: Sexual Minorities, Minority Stress, Psychological Distress, Self-Esteem, Stigma.

\footnotetext{
${ }^{1}$ Emma G. Fredrick, Ph.D., is an Assistant Professor in the Department of Psychology at Marist College. She earned a PhD in experimental psychology from East Tennessee State University in 2017. Her research lies at the intersection of social and health psychology. In particular, she focuses on the ways in which various forms of stigma impact the mental and physical health of minorities, particularly sexual and gender minorities. Address correspondence to: Emma G. Fredrick, e-mail:

Emma.Fredrick@,Marist.edu.

Stacey L. Williams, Ph.D., is a Professor in the Department of Psychology at East Tennessee State University and directs the Social Issues and Relations Laboratory (SIRL). She earned a PhD in social - health psychology at Kent State University in 2004, and then completed an NIMH postdoctoral fellowship at the Institute for Social Research, University of Michigan. Her research on the lived experience of individuals with stigmatized identities which has previously been funded by NIH, focuses on sexual and gender minority stress and health. Address correspondence to: Stacey L. Williams, email: WILLIASL@mail.etsu.edu.
} 